\title{
The Effectiveness of Self Hypnosis to Overcome Insomnia: A Case Study
}

\author{
Suad M. A. Sulaiman ${ }^{1}$ \\ ${ }^{1}$ College of Education, Sultan Qaboos University, Muscat, Oman \\ Correspondence: Suad Sulaiman, College of Education, Sultan Qaboos University, Muscat, Oman. Tel: \\ 968-9-944-4646. E-mail: dr.suad.sulaiman@gmail.com
}

Received: August 6, 2013

doi:10.5539/ijps.v6n1p45

\author{
Accepted: September 10, $2013 \quad$ Online Published: January 24, 2014 \\ URL: http://dx.doi.org/10.5539/ijps.v6n1p45
}

\begin{abstract}
This study aimed at investigating the effectiveness of implementing a self- hypnosis program as a skill for enhancing the quality of life for individuals suffering from insomnia. It involved a case study of one male student. The participant had suffered from insomnia for six months in addition to an obsessive-compulsive disorder. The self-hypnosis program was assessed to be suitable for insomnia cases. Pre-tests data were taken for a six day period before training. The counsellor then trained the participant for three sessions, followed by six sessions of self-training by the participant. On each of the self-training days, the participant registered post-test data for three dependant variables.
\end{abstract}

Results of the means show that the program of self-hypnosis is effective in reducing the time required to sleep, an increase in the time remaining asleep, and a reduction in the number of awake periods during sleep sessions. Discussion and recommendations were made.

Keywords: self-hypnosis, insomnia, counsellor, self-training program

\section{Introduction}

Insomnia is considered as a severe sleep disorder, which negatively affects the quality of life. Insomnia is a common problem that can affect any person, at any time. Medically, it is defined as the inability to sleep, or sleeping less than four hours per day, bearing in mind that it does not refer to people who choose to stay awake.

There are three types of insomnia: severe insomnia for a short period of time, chronic insomnia that can span from one night to several weeks and is the more common form, and insomnia caused by chronic anxiety. This third kind of interrupted sleep appears intermittently and may last from three weeks to six months (Mead, 2006).

There are psychological and physiological causes for insomnia. The psychological causes include depression (Chang et. al., 2012; \& Sing \&Wong, 2010), pessimism, stress, (Sing \& Wong, 2010), anxiety, and obsessive compulsiveness. Insomnia can also be a reaction to emotional shock, an example of which is hysterical insomnia, or obsessive thoughts which control the sleeper's brain.

The physiological causes of insomnia can be related to a thyroid gland disorder, neuroses disorders, or the side effects of certain medication (Buysse et al., 1989). According to results of some experimental studies, deep sleep during the first hour of the sleep contributes to deep muscular relaxation.

As with other illnesses and conditions, insomnia is represented in many self-reports and may have different criteria, such as:

1) Required time to begin sleep

2) Actual sleep time

3) Deep sleep

4) Duration of interrupted sleep

5) Walking while sleeping as a result of sleep diversion (Beck- Little \& Weinrich, 1998).

Insomnia negatively influences people's lifestyles since its symptoms correlate more with the characteristics of life enjoyment than to a meaningful life, (Hamilton et al., 2007). The relationship between insomnia, illness, and lower levels of wellbeing is well known. It may contribute to smoking, delinquency, careless driving, 
inappropriate behaviours (Catrett \& Gaultnet, 2009), and suicide, (Goldstein, Bridge, \& Brent, 2008). There are several counselling techniques designed to treat counselee's with insomnia (Milner \& Belicki, 2010). Self hypnosis strategies have been used to overcome insomnia problems and to increase sleeping hours, (Chertok, 1981).

The word self-hypnosis comes from Greek and means sleeping. In some instances, self- hypnosis is similar to normal sleeping. That is, it can be a form of deep relaxation that is different from sleeping in such a way it does not allow for complete loss of control. Throughout the hypnosis process, the person can respond to the surrounding events and sounds. Usually, the self-hypnosis process is applied through closing the eyes to facilitate concentration and imagination, and can be accomplished while the eyes are open, (Szabe, 2006; Miller, 1979).

Self-hypnosis helps in putting real thoughts and events into imagination, and how the person behaves in relation to such events in real life. As an example, if the person is watching a violent event, the mind and body will respond in similar ways to the person involved in the event being watched. The body muscles become tensed, the stomach may ache, heart beat increases and breathing becomes difficult (Waxman, 1985).

People are familiar with hypnosis; they practise hypnosis when they concentrate on certain matters which are of interest to them. They may as well be hypnotized without any perceived chains and barriers. Interestingly, day dreams are another example of self-hypnosis. In addition, driving a car for a long distance is considered self-hypnosis (such as losing memory about different events from the journey). People are self-hypnotizing every time they remember their shopping list, past events, watch T.V, or recall strong fears toward some past events. In all conditions, self- hypnosis cases include the following (Fromm \& Shor, 1979):

1) Reduction of movement and energy with an increase in relaxation: the sleeper experiences decreased movement, muscular activity and vital energy.

2) Lying down in a very comfortable position: putting each part of the body in the right position.

3) Understanding words in their literal meaning as pronounced, so that when asking the sleeper if they could tell you their age, the answer should only be "yes".

4) Lowering their attention level: background visual and audio stimulus are realized but not considered important and therefore ignored.

5) Increase in the sleeper's acceptance level of external effects. For example, if you told the person that they feel strong heaviness in their right arm, the person would really feel that, and understands that heaviness in reality (Beaton \& Voge, 1998).

Freud is considered the spiritual father for suggestive hypnosis as remedial treatment (Strus, 1998). Hypnosis in applied in many fields. It has provided an effective contribution for improving the quality of life through overcoming certain behaviours or bad habits, such as smoking, food disorders such as obesity or loss of appetite, insomnia or other sleep disturbances. Hypnosis also helps in discovering crimes by stimulating the memory to remember some indications like numbers or some forgotten events. For the most part, the people benefiting from the application of self-hypnosis exercises are the people who suffer from problems. Others use hypnosis to reactivate old memories or past experiences. Some specialists and therapists use self-hypnosis to discover the hidden truth (Wong, 2003).

Some people are victims of sexual abuse or aggression. In these cases, they are hypnotized to a pre conscious stage to help them remember some of the details of their past experiences. At the same time; however, suggestive hypnosis can be dangerous because the individual may be harmed by the negative suggestions that he/she may receives from the therapist (Bonnett, 1994).

Self suggestive hypnosis is a process that includes a hypnotist and the subject who is to be controlled. To complete the process of hypnosis, the hypnotist must find ways and movements to control the concentration of the individual, to provide the stimulus for very deep muscle relaxation, and finally to provide a high degree of suggestion. Hypnosis may happen under different social atmospheres such as classrooms and other places (LeCron, 1971).

What is known about self-hypnosis and which may interfere with the degree of response comes from the results of studies conducted by subjects. There is no doubt that there is a correlation between the imagined stage and responding to self hypnosis suggestions. We know that imaginative people are better able to respond to self-hypnosis exercises, compared to others who find it difficult to respond to hypnosis suggestions. Those in the latter category believe that self-hypnosis is a random movement that does not have meaning, and it does not 
affect their level of consciousness. Therefore, the process of self-hypnosis may be marred by a lot of misconceptions, because its applicability is limited by differences in a person's susceptibility to suggestions and to their acceptance of it as a therapeutic technique (Waxman \& David, 1985).

The process of self-hypnosis is accomplished through cooperation between the counsellor and the person suffering from sleep disorder. Each one learns and trains for their role. In addition, they must reinforce the other party by responding appropriately to the hypnosis. The hypnotist provides the subject with suggestions and the subject, in turn, has to respond to those suggestions audibly. Then the counsellor repeats the suggestions and movements that captured the focus and attention of the counselee (Strus, 1998).

Self-hypnosis is a learned behavior. It is a scientific approach and an effective technique that helps and enhances the human capacity to change; suggestive hypnotherapy can create the desired change in behavior. As a result, the person can live in good health; both psychologically and physically. The positive impact of self-hypnosis training has become apparent pertaining that it must be practiced for at least two days. For the individual to become professional in the skill of self-hypnosis, the person should exercise for one day at least each week. In addition, the subject should be urged to complete some suggestion exercises every day.

\subsection{Procedural Definitions}

Self-hypnosis is a series of exercises, training and suggestions that begin by muscular relaxation, followed by making suggestions that help the participant enter sleep. It is defined in the study training program, which will be referred to later.

\subsection{Importance of the Study}

This study is a qualitative case study, and such a type of study is rarely conducted in the Arab world (according to the researcher's point of view). This study is also characterized by a self-hypnosis training program. The importance of this study was an attempt to highlight the effectiveness of suggestive a self-hypnosis program, and to give trainees the ability to facilitate access to sleep and prevent sleep disturbance, and to increase the number of sleep hours. According to individual counselling skills, this study came with descriptive experimental evidence of the impact of self-hypnosis training in facilitating the individual's ability to sleep and overcome insomnia. This will provide training strategies and skills that can help facilitating individual's sleeping processes and; thus, reflect positively on their quality of life.

In this study, the subject will learn to apply self-hypnosis by employing more positive ideas and fantasies to help him relax and reduce stress levels and obsessive thoughts. He can as well be trained to do these exercises alone and safely. Most reports indicate a lack of negative side effects after practising hypnosis exercises.

\subsection{Problem of the Study}

The researcher noticed that a number of students suffer from insomnia and have difficulty entering sleep. Moreover, it has been noticed that there is a difficulty in applying some cognitive or behavioural strategies to help overcome insomnia. In addition, some individuals showed very severe resistance in responding to suggestions that come from the counsellor. They feared that the counsellor would then gain insight into their deep personal self. As a result, a new strategy to overcome this problem had to be found, and that was to train the individual to carry out self-hypnosis exercises and apply them alone at bedtime. It is possible to train students on the skills of self- hypnosis in order to overcome sleep problems (Hawkins \& Polemikos, 2002). The student will "live" the counselling experience out of the counselling room (Freeman, 2007). Insomnia is one of the most common challenges that go hand in hand with a number of mental and physical diseases. In addition, it is associated with symptoms of depression, anxiety or other physical problems.

Through searching for an effective method to get rid of insomnia, it has been found that the strategy of self-hypnosis has a great advantage due to its direct association with sleep. In light of the foregoing factors, concerns related to self-suggestive hypnotherapy, the extent of insomnia as a problem, and its impact on human life, this study can contribute to answering the following questions:

1) Is there an effect of self-suggestive hypnosis on reducing the length of time taken to enter sleep?

2) Is there an effect of self-suggestive hypnosis on the increase of real sleep duration?

3) Does self-hypnosis help overcome periods of interruption during sleeping?

\subsection{Study Limitation}

The study sample consists intentionally of the selection of students who suffer from insomnia. The present study results could not be generalized to all individuals who suffer from insomnia based on the results of one student 
suffering from insomnia. Moreover, the limitation of this study includes individual differences in acceptance of self- hypnosis and their responses to it. Finally, the limitation of this study is determined by the gender of the selected sample, who was one male student only.

\subsection{Previous Studies}

Studies have shown the effectiveness of hypnosis in treating the symptoms of insomnia, headaches, crises, stress, and anxiety. Self- hypnosis may not affect those who suffer from the symptoms of mental disorders, psychosis, persons who suffer severe mental retardation, schizophrenia and paranoia, or people who have a sense of insecurity and do not want to reveal themselves. The studies conducted on this subject have been arranged in a chronological order of publication:

Harrison and Van Hanghan (2011) conducted a study on 73 gifted and 143 typical middle and high school adolescents who were given a death anxiety questionnaire, a fear of the unknown scale, an insomnia scale, and an over excitabilities questionnaire. Results revealed higher levels of over excitability in students who also presented higher anxiety and insomnia. The study suggested that some gifted students who experience over excitability, insomnia, fear of the unknown and/or death anxiety may benefit from relaxation techniques, fantasy gaming, bibliotherapy, social emotional curriculum and counselling.

In another study, Vail-Smith, Felts, and Becker (2009) administered the Sleep Quality Index (SQI) and the Center for Disease Control's National College Health Risk Survey (NCHRS) to 859 undergraduates at a large south-eastern university. Results indicated that $76.6 \%$ reported occasional sleep problems and $11.8 \%$ experienced poor sleep quality. Among the problems reported, "General morning tiredness" (82\%) and "insomnia" (28\%) were the most common (p...). Certain health risk behaviours appear to be associated with poor sleep quality including fighting, suicide inclination, smoking, and alcohol use.

Younus's carried out a study in 2003 entitled: depression and loss of control of the mind. The first objective of the study was to observe the effect of self-hypnosis on the quality of life in patients with insomnia due to suffering from chronic cancer. The second objective was to know the impact of self-hypnosis to overcome fatigue and exhaustion in these cases. The study sample consisted of ten (10) people who volunteered for four hour sessions per week on self-hypnosis training. The results of the analysis revealed a statistically significant reduction in symptoms of fatigue and exhaustion as well as an increase and improvement in the quality of life, including overcoming the problem of insomnia.

Also, Marnatani and Cirnino (2002) conducted a study of alternative medical associations in treating health psychology problems. There is evidence for the effectiveness of alternative medicine in overcoming illnesses. For example, massage contributes to reducing anxiety and stress. Moreover, self-hypnosis contributes to reducing the incidence of pain and helps reduce cases of insomnia. The aim of this article was to educate physicians and practitioners about the importance of treating patients with techniques that have proven usefulness and effectiveness.

The impact of self-hypnosis as a regulator of the immune system cells during periods of tension and acute stress was studied by Kieccolt et al. (2002). They found that training the skills of self hypnosis boosted the functions of immune system cells, and as a result there was an improved level of sleep condition with the study sample.

Hawkins and Polemikos (2002) studied the effect of self- hypnosis treatment for sleep problems among patients who experienced painful experiences. The purpose of this study was to overcome the symptoms of insomnia associated with shock including horror and dismay. The treatment plan included training in self-suggestive hypnosis. The results showed statistical significance in the effectiveness of overcoming problems associated with sleep. The data were collected depending on the sleep agenda management for Southampton, in addition to individual interviews. The study also found that it is possible to train students on the skills of self- hypnosis in order to overcome sleep problems, as well as through group counselling.

A study entitled "Overcoming anxiety through self- hypnosis" (Sprinkle, 1997) focused on training participants on three basic skills: to learn an eye muscle relaxation technique, to focus on remembering, and imagining situations and pleasant, comfortable events. The student participants were encouraged to increase their capacity of self-control and controlling emotions. The sample of the study responded to these suggestions by reducing anxiety levels and an exhibited an improvement in their quality of life

A study entitled, "Self-hypnosis as an alternative method and program for the treatment of alcoholism" was carried out by Young, (1996). The sample consisted of (40) patients: (23) males and (17) females, who were being treated for alcoholism. The sample was randomly divided into two groups, the experimental and the control group. In each group of (20) individuals, pre measurements were taken for a number of psychological 
symptoms, including the number of hours of sleep. The results showed the effects of suggestive hypnosis: it improved stress management skills by $95 \%$; altered the subjects' pulse rate by $80 \%$; as well as improving individual's ability to sleep by $65 \%$.

A study by Laplante (1991) explored the extent to which students use self-hypnosis strategies and sleeping suggestion. The study sample consisted of 62 students, all of whom completed the Personality Test multi-faceted questionnaire, who were distributed into two groups, the experimental and the control group. The experimental group students were trained on the skills of self -hypnosis for a period of seven sessions (for 45 minutes per session). It demonstrated that the students of the experimental group showed greater efficiency in study skills and entering sleep easily, while there appeared no differences between the two groups regarding the effectiveness of memory.

Buonanotte (1984) conducted a study entitled "The practical applications of suggestive self-hypnosis in solving educational problems". The study sample consisted of three students who failed in their studies. The results of this study demonstrated that self-hypnosis was an effective tool in dealing with academic problems. It demonstrated an increased ability of elementary school students in reading skills and subsequent modification of students' attitudes toward learning. The participants also exhibited the desire to sleep and to overcome the problems of insomnia.

In a study entitled "Sleep deprivation and its ease of entry through self-hypnosis", Albert (1975) found that suggestive self- hypnosis was effective in facilitating sleep on time in members of an experimental group who suffered from insomnia. Results were significantly compared to the control group members who did not show any change in the time it took them to sleep. This discrepancy was due to the effectiveness of a self-hypnosis program to facilitate the process of sleep.

From the review of these studies the researcher found that self-hypnosis strategy can be effective in improving the participants' ability to sleep, sleep condition, quality of life, and sense of satisfaction. It is possible to train students on self-hypnosis skills in order to overcome their sleep disturbances through group counselling. In addition, self-hypnosis was an effective tool in dealing with academic problems, lowering levels of anxiety, stress, and in regulating heart and breath rate.

\section{Methodology and Procedures}

\subsection{Sample of the Study}

The study sample consisted of one male student (19 years old) suffering from insomnia due to the presence of authoritarian and obsessive compulsive ideas. It focused on the lack of capacity and capability to sleep in such a way sleeping became impossible. This case was followed for a period of two semesters consecutively, without success in overcoming the problem of insomnia. Note that this student also was suffering from low achievement (a probation student), which was causing him a lot of anxiety and stress.

\subsection{Study Tools}

The study included two tools: a verbal report list, and a training program in self-hypnosis.

1) Verbal report list, these lists have been used to record the length of time it takes to sleep, the number of times sleep was interrupted, and the duration of time taken to re-enter into sleep. It also included the extent to which the participant felt comfortable with the activity. It offered opportunities for the counselee to learn what had been developed, discussed and trained in counselling session, and an opportunity for gathering data (Freeman, 2007). Medical standards have been adopted in determining levels of insomnia and sleep hours. Accordingly, the following criteria were identified to assess the degree of insomnia every morning during the program.

A. Sleeping for less than four hours per day.

B. Difficulty in entering sleep: the duration was for three hours at least.

C. Periods of interruption during sleep: at least reaches three times per night.

2) The training program on self-hypnosis was shown to 6 people who specialize in the field of therapy and counselling for their opinion. The following lists the steps in the training program on self-hypnosis (Davis, Eshelman, \& Mckay, 2000).

The first step in self-hypnosis is learning the power of suggestion; the following exercises can shed light on the strength of suggestion.

First Example:

1) Stand and close your eyes and imagine yourself carrying a bag in your right hand. 
2) Imagine that the bag is too heavy making your body bend down more and more and more, more, suggestions.

3) After two to three minutes open your eyes and note the changes in your body and body posture.

4) Close your eyes again and imagine that the power of the wind is pushing you back very strongly. Be very alert to whether your body responds to this exciting strong stimulus through your imagination.

Second Example:

1) Extend your arms forward at shoulder level, close your eyes, and imagine: There is a heavy weight linked to your right arm making you feel tired and unable to continue carrying the weight.

2) Imagine another weight added to your right hand; you feel tiredness which begins to spread to your right arm.

3) Now imagine that a big balloon filled with helium is tied to the left arm. The balloon begins to rise more and more, and your left hand goes up with it more and more. The balloon rises up higher and higher.

4) Open your eyes now and notice the level of your hands compared to their previous positions.

Most people who have experienced these exercises have shown that their bodies and their organs have moved and changed and developed in response to these suggestions, if you did not notice any changes, you should carry out these exercises bilaterally or collectively many times, if you did not notice any changes or differences in the movements, self-hypnosis is not a good fit for you.

Learning self- hypnosis:

The second step of self-hypnosis skill is learning how to learn self-hypnosis suggestion. The following are some of the suggestions that may help you increase your ability to adjust and change your usual pattern of personality or goals.

1) Position: Sit in a comfortable chair with a suitable place to rest your arms, hands, neck and head. Choose a convenient and appropriate position to put your legs and feet on the ground. Make your clothing loose and comfortable at your waist and neck. Take off your glasses, watch any other things. Sit in this position for a sufficient period of time without any interruption.

2) Keyword: Choose something that relates to the problem you have, and select a target to strive for. For example, if you are required to present a skilful display, the intended goal is to be relaxed. Repeat the word "relax" now "relax" now. Repeat this word several times at the moment of closing your eyes, so that it coincides with the state of muscle relaxation. As you hear and see the sounds and favorite colors in your room, more repetitions and practice will make you able to reach self-hypnosis.

3) Breathing: after you close your eyes, take a deep breath. Breathe deeply through your stomach so that a sense of relaxation spreads in all parts of the body.

4) Muscle relaxation: You are able to relax the muscles of the legs, arms, face, neck, shoulders, chest, and stomach. During the relaxation of those muscles, your weight becomes heavier and heavier. These are practical training for muscle relaxation techniques.

5) Choose your favourite place and start counting descending from (10 to zero) and at each number you will be more relaxed and be in the best places. And when you reach the number zero you will reach maximum relaxation and be in a beautiful place you love.

6) Deep Relaxation: Use the following key suggestions more and more until you feel assured and relaxed.

A. Relax deeper, deeper, and deeper.

B. You feel more and more relaxed, also more comfortable and reassured.

C. Calm and serenity ...then peace and quiet

D. Deeper even more and more and more into deep relaxation.

The following is a summary of the guidelines and rules in the process of successfully practicing the skill:

1) Give yourself 20 minutes to enter into the state of deep self-hypnosis.

2) Do not be worried about the success or what to do after it. Suggestive self-hypnosis will become easier with practice.

3) Always take the time to do deep muscular relaxation and take a very deep breath.

4) Use some positive phrases like: I feel a very heavy weight in my arms and head.

5) Use some attribute words such as: sleepy, comfortable, reassured ... 
6) Repeat such sentences and words until you start actually feeling that self-hypnosis is influencing you.

7) Use the skill of creative imagination, for example: to become heavier, imagine your leg is a very long connecting tube and to become lighter imagine a very large balloon filled with helium that raises you to the top so you are above the clouds.

A preliminary model to increase the capacity for self-hypnosis:

The third step in self -hypnosis is recordings that include some suggestions, so listen to the recording within the range of low sound, and the calm and simple words. Always make simple pauses between each sentence, so speech becomes slow and gentle, which helps you to relax and accept suggestions.

Here is a sample of self-hypnosis training:

Sit in a comfortable place stretching both your legs and arms. And make your eyes concentrate directly on a specific point in front of you. Take a deep breath with very deep relaxation, bringing oxygen to the bottom of the stomach ... Again take a very deep breath ... Now you feel tired in your eyes. Make your eyes half shut and take a deep breath which brings relaxation ... Again, do so again ... Your eyes seem now heavier and heavier ... Close your eyes now, what are you thinking now? What is the word or sentence that you are thinking of now?

Now you can start muscle relaxation in your body ... Let your legs relax ... Then let them feel extreme heaviness ... heavier, heavier and in turn you feel more and more relaxed. Arms also are heavier and they weigh more now ... then heavier ... You feel relaxed whenever you start feeling the weight of your arms, the tension goes without returning from all parts of your body. You now feel extreme heaviness in your legs and arms; also you feel deep muscle relaxation along with heaviness ... There is no tension ... I feel relaxed and heavy. Now your face is very relaxed, and the neck muscles, head, cheeks, are comfortable and very reassured. Also your jaw begins to relax and releases tension ... As well as your lips, you lose control of them and they seem to relax more and more and deeper and deeper

Now your neck and shoulders begin to relax where you feel relaxed and absolute quiet too ... Now you feel your shoulders falling on the couch ... You have very deep muscle relaxation ... Now and again take a very deep breath ... Let oxygen and relaxation spread throughout all your body and organs ... Take a deep breath again and feel very comfortable and reassured and relaxed.

Now you feel relaxed in your stomach and chest, relax your muscles deeper ... deeper ... deeper. Now you feel sleepy ... more ... and more ... deeply relaxed and comfortable ... deep ... deep and deep.

Now go to your special place ... This place is very safe ... You are now counting down from ten to zero and with each number you count, you reach to a deeper degree of relaxation. Deeper ... Relax ... deeper ... relax and start now counting ten ... nine ... eight ... zero. (Can be re-counted twice or more).

Now imagine the colors, sounds and shapes in your own place. ... Smell your own lovely place ... Imagine and look at it ... Feel it ... smell it. Hear it ... Speak it. ... You can feel secure and trust in your own place. And now you feel comfortable in your own place.

Now you feel the flow is deep and far away ... then you go away ... The more distanced you become, the more comfortable and sleepy and relaxed you are.

Now, you feel more and more sleepy. Entering sleep more and more, and then you are fully relaxed. You are very satisfied and reassured, (pause for a short time in your own distinctive place which you prefer). And now you know that you can sleep quietly. (Give yourself the opportunity to repeat it several times).

Now, when you feel you want to return to the previous situation and become awake, feel active and refreshed, start counting from one to ten and when you reach ten, it means that you are very active and you wake up. Now start ... One ... two ... three ... you wake up now more and more ... five ... six ... seven ... wake up more and with more energy ... Eight ... Nine, start to open your eyes ... ten you are fully awake and refreshed.

The fourth step of the self-hypnosis skill is to learn some body movements. Below are some of the skills that will help you to enter hypnotherapy from (30) seconds to two minutes. The following are some examples:

1) Make a pendulum from a pen or a ring or anything and a piece of string about 25 centimetres long. Hold it in one hand and start to watch the movement of the object. Give yourself a suggestion of relaxation and deep sleep. If you want to close your eyes imagine a candle light instead, take a very deep breath several times. Allow yourself to breathe deeply several times ... Imagine that candle light more ... tell yourself that you are when you enter the state of hypnosis, your hand will relax more and thus the pendulum will fall from your hand, start counting down from ten to zero. 
2) Fall of the pen: This technique is similar to the fall of the pendulum technique except that the pen is held with the thumb and forefinger and is directed towards the bottom, with sequential movements in front of the eyes.

3) Repeat the word "yes", think carefully of the word "yes" more and more. Also, focus on the candle light, go down the stairs to the bottom and down and through, think of the thought of the word yes more and more. The more you go down the more you

4) Place a coin in the palm of your hand and make your hand turn slowly, so the piece falls from your hand and then close your eyes to begin self-suggestive hypnosis.

5) Focus your eyes on a specific point above your level of sight. Try to narrow your focal point even more, until your eyes lose focus. Close your eyes now with the feeling of drowsy to increase the room of sleeping twice or more.

6) Key word or phrase, breathe deeply and slowly and repeat the keyword or phrase you use, and while you repeat that word, close your eyes and focus in order to induce the state of self-hypnosis.

These suggested methods become useful and have an effect when you become skilful in using self-hypnosis. Always remember to end up with suggestions that focus on the active waking up with feelings of comfort and enjoyment.

Five fingers exercises:

Here are some exercises that have been used very effectively for relaxation. March (2006) considers the following steps; learning and memorizing it will help you to enter into the state of self-hypnosis.

1) Touch your thumb with your index finger, and with this movement go back to past memories and remember the times that you felt such health and physical pleasure, such as those times that follow swimming exercises, or games of tennis or some other sport activities.

2) Touch your thumb with the middle finger, and while you're doing it, remember enjoyable, pleasure and fun experience that you spent with the ones you love and enjoyed sitting down with them and their friendship.

3) Touch the thumb with your "ring finger" and while you do so, remember some beautiful and lovely compliments which you have received. Try truly accepting them and feel their meaning by showing your appreciation to the person who complimented you. You are now in fact exchanging courtesy.

4) Touch the thumb finger with the little finger while you remember more affectionate and distinctive places. Try to imagine you are staying and living in it from now on; feel that you are enjoying your life by staying in it.

The five fingers exercise does not need more than ten minutes to be accomplished, but it helps to increase the feeling of security and confidence and psychological comfort through overcoming tension and stress.

Self-hypnosis exercises:

The fifth and the most important step in self-hypnosis is learning how to give yourself positive suggestions to help you change. To achieve the best results say these suggestions when you are in a comfortable and relaxed position, especially when you are in your best special place.

Remember that suggestions are self-thoughts or fantasies that affect previous experiences you have had. The following are a list of instructions that you must retain in your memory when you recall self-suggestions to be more effective:

1) Tell yourself that you are going to be very quiet in the stillness, trust and confidence. Also self-control all body movements.

2) Be positive. Avoid negative suggestive words like "I will not feel tired tonight".

3) Be nice. Try to say "I could feel relaxed and refreshed tonight" instead of saying "I will feel relaxed and refreshed tonight", even though some people are more responsive to commands. You can choose from the past experiences whichever is better for you.

4) Repeat the words "drowsiness will come now", repeat it at least three times.

5) Type suggestions that help you to sleep deeply. Focus on describing positive, pleasant, fun situations you are experiencing now. Also you can write the positive suggestions to overcome a lot of fears and other problems such as fear of the dark, fear of disease and so on.

Self-suggestive hypnosis for specific problems 
This is the sixth optional step which must be taken into account if you want to solve specific life problems. Here we must identify the problem, for example, the inability to sleep or a sense of insomnia. Before you begin the process of self- hypnosis there are some guidelines that must be taken into account such as:

1) Select your problem and your goals. Do you find it difficult to go to sleep or in staying asleep? Or is sleep tiring you? Are you having trouble getting up early? When you define the problem, you can easily put the goals in the context of positive suggestion, for example: I can sleep quickly and quietly. I will wake up from sleep active and energized, or as soon as I sleep I will continue sleeping deeply during the night.

2) Select the external factors that contribute to the problem: Ask yourself what are the factors and causes that lead to your lack of sleep. Is it an uncomfortable room or noise or light, or is there a lot of stimuli during the night?

3) Inform yourself of the underlying causes of the problem, for example, people who suffer from difficulty in sleeping focus on the time, and say things to themselves such as "I'll will not be able to sleep until midnight. I know that I will not sleep at all". We must use a method to stop reinforcing these irrational thoughts and control our anxiety. Here are some suggestions that can be used before going to sleep:

A. Turn the clock around so you cannot see the clock face. Control your thoughts by saying to yourself that you are now very relaxed, comfortable and calm.

B. If you are inclined to think about issues and negative attitudes which you cannot control, instead, try to think of positive things you did during your day.

C. If you have time to resolve your concerns and problems, write these problems on a list before you go to sleep and then make an agreement with yourself to postpone these problems until the morning when you are active and content, without worry.

Record suggestions to overcome the problem you are experiencing.

Now you're in your favoured special place and there is nowhere else to go. There is nothing you can do. Just rest, stretch and lie down, and sleep comfortably and flow. You are drifting and drifting in deep then deeper to sleep. Imagine the positive things that you can think of, and think about them in order to allow yourself to sleep comfortably. Your positive thoughts now are real. You are liberated and free of the negative feelings, thoughts, you have overcome the tension and stress that can affect your mind, body, and thoughts. Positive emotions and constructive ideas began to grow bigger and bigger now. Also, they become bigger whenever there is a flow and drift towards relaxation. Just allow yourself to enter gracefully and quietly to sleep, allow these positive events to enter and affect your mind's voice only, leading you to sleep and rest.

Now be aware and know how much you are relaxed and comfortable. So continue to relax. Your head and shoulders are in the right place. Your back is lying and relieved. Do not care about all the sounds that you hear only your voice. You may face some painful, negative, and anxious experiences. Also, these experiences can overwhelm the content of your thinking and your comfort and your response to sleep. Simply try to take these ideas and drag or sweep them away and remove them like we sweep and remove dirt from the ground. Put these ideas in a bag, and place them in a container, this container is a beautiful pot and has a lid, place the lid on the pot. Put the pot on a rack in a closet, you can refer to the pot at another appropriate time. That time does not affect your sleep and relaxation. Whenever a negative and uncomfortable idea emerges again, place it in the pot and then put the lid on it. Return the pot to the shelf in the closet and do not allow those thoughts to bother and affect your sleep again. Then continue your deep sleep and beautiful relaxing.

Move your thoughts now to a stage of positive thinking. Make these ideas fly around in your mind, these ideas like I'm a wonderful person "pause" I've done a lot of things, "stop." I have achieved a lot of goals, "pause" Make these ideas shower and multiply, let them flow easily, so that they become stronger and stronger whenever you enter a deep sleep.

Maybe you see those ideas are less clear and are faint, and they will become more obscure as you become more relaxed and sleepy. Only imagine yourself in a special and exceptional place. You are smiling, feeling comfortable, pleased and in deep relaxation "stop." From this privileged place, you can easily pass on to a deep sleep; sleep isn't annoying or inconvenient. You are sleeping in a quiet night, no noise is disturbing you. It is a very quiet night. If you want to wake up again you have to just remember the privileged place for you and that you enjoy sleep and deep tranquillity. The breathing is starting now to be quieter and more relaxed, also the storm of ideas in your mind has become calm, calm down. ... more and more, and then relax. You travelled and floated into a restful sleep, ideas are not interrupting your mind during the night, you will wake up just in time in the morning and you will feel comfortable and active. 
Now there is nothing to do, there isn't anything you can think of except to enjoy your special and distinctive place. Your privileged place is safe for you. It makes you feel relaxed. Just imagine how you relax when you are in your own place. Perhaps you become more aware, perhaps you are now more clearly aware and the distinctive smell of your place is nice, or maybe you are now more aware of the different sounds around your place such as distinctive voices of birds and the sound of trickling water and the birds over the rocks and trees. You are probably more aware of the cold winter and the snow or the heat of the sun, just remember these experiences, move more and more towards deep sleep. Your body is now more heavy and relaxed so become relax, just go to sleep ... sleep ... sleep ... sleep.

\section{Study procedures}

Study procedures have passed the following phases:

1) Translation and preparation of the training program based on self-hypnosis.

2) Check the veracity of the training program by submitting it to number of arbitrators in this field to ensure its suitability for the problem of the study.

3) Selection of the study sample, a student who suffers from chronic insomnia because of obsessive compulsive ideas.

4) Determine cutting points to take measurements on three dimensions as follow: sleep duration, the time it takes to enter into sleep, and the number of times of sleep disruption.

5) Application of the training program for a period of three training sessions after training the student self-hypnosis for a period of six days.

6) Give instructions to the person to put paper and pen next to the bed to record the data required from him after training on self-hypnosis each morning.

7) Taking repeated dimensional measurements over the six days since the first day of training on self-hypnosis.

\section{Results and Discussion}

The analysis of results were based on qualitative and quantitative information of a descriptive case, the following table represents the average measurements before and after repeated depended variable.

Table 1. Average measurements before and after repeated depended variables

\begin{tabular}{lllllll}
\hline Variables & \multicolumn{2}{l}{ Time to enter sleep } & \multicolumn{2}{l}{ Sleeping Time } & \multicolumn{2}{l}{ Sleep Disturbance } \\
\cline { 1 - 6 } & Before & After & Before & After & Before & After \\
\cline { 1 - 5 } & 2 & 0.30 & 5 & 30.6 & 3 & 1 \\
2 & 30.2 & 1 & 4 & 30.5 & 2 & 0 \\
3 & 3 & 0.30 & 4 & 30.6 & 3 & 1 \\
4 & 1 & 0.30 & 5 & 30.5 & 4 & 0 \\
5 & 0.30 & 0.30 & 30.4 & 30.4 & 2 & 0 \\
6 & 3 & 0.30 & 4 & 30.6 & 3 & 2 \\
Average & 2 & 0.35 & 35.4 & 45.5 & 83.2 & 0.66 \\
\hline
\end{tabular}

The previous table shows that the average time taken to enter sleep had reduced from two hours to thirty-five minutes over the six days on repeated measurements, which was an average decrease of an hour and twenty-five minutes. It also increased the time spent in the sleep period from 4.35 hours to 5.45 hours, an average of one hour and ten minutes. Also the number of times waking up decreased from 2.83 to 0.66 , an average of 2.17 times. Accordingly, the results of the descriptive analysis showed differences in the averages for pre and post measurements. Figure 1 clarifies this improvement; the graphic representation shows the arithmetic averages of the pre and post measurement of insomnia variables: 


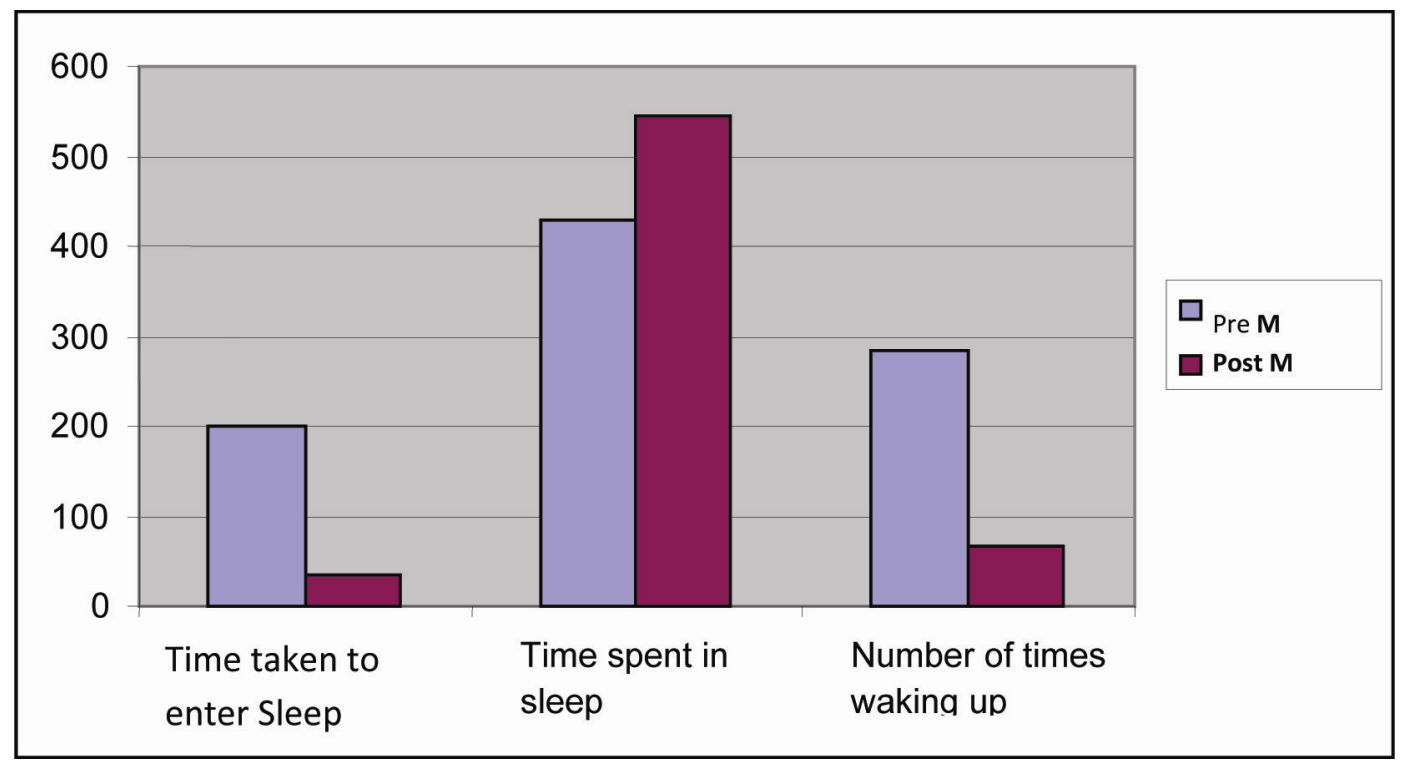

Figure 1. Graphical representation of arithmetic averages for pre and post measurement variables of insomnia

The results of this study are consistent with most of the results of previous studies, which explain that self-hypnosis is linked directly with sleep. Also, self-hypnosis can be applied to overcome other problems. Suggestions taught to the participant enabled him to enter a phase of sleep. Moreover, it included suppression of participant's negative compulsive thoughts and control of their appearance, on the other hand, it focused on positive thoughts.

The case reported that there was a noticeable change felt after exercising daily. This represented changes in increased hours of sleep and ease of sleep, which in turn impacted positively on the quality of life of the participant, for example improved social life. The subject also was able to go to bed without anxiety or fear that he had felt earlier.

\section{Recommendations}

The training of self-hypnosis was effective in overcoming the problem of insomnia and sleeping difficulties. The study recommends generalizing these exercises of self-hypnosis practice for the above goals. The results of this study are limited to the study sample, and therefore conducting further descriptive and experimental research would be very useful. In addition, the hypotheses tests and results can be generalized to others. Finally, replacing medication for Insomnia sufferer with self- hypnosis exercises (only when possible) in parallel consulting with psychiatrist.

\section{References}

Albert, I. B. (1975). Dream Deprivation and Facilitation with hypnosis. Journal of Abnormal psychology, 84(3), 267-271. http://dx.doi.org/10.1037/h0076652

Beaton, S. R., \& Voge, S. A. (1998). Measurements for Long-Term Care. Thousand Oaks, CA: Sage Publications.

Beck-Little, R., \& Weinrich, S. P. (1998). Assessment and Management of Sleep Disorders in the Elderly. Journal of Gerontological Nursing, 24(4), 21-29.

Bonnett, O. T. (1994). Confessions of a healer: The truth from an unconventional family doctor. Aspen, Colo.: MacMurray \& Beck.

Buonanotte, W. (1984). The Application of hypnosis and hypnopaedia as a Modality for educational problem. Dissertation Abstracts.

Buysse, D. J., Reynolds III, C. F., Monk, T. H., Berman, S. R., \& Kupfer, D. J. (1989). The Pittsburgh Sleep Quality Index: A New Instrument for Psychiatric Practice and Research. Journal of Psychiatric Research, 28(2), 193-213. 
Catrett, C. D., \& Gaultney, J. F. (2009). Possible Insomnia Predicts some Risky Behavior among Adolescents when Controlling for Depressive Symptoms. Journal of Genetic Psychology, 170(4), 287. http://dx.doi.org/10.1080/00221320903218331

Chertok, L. (1981). Sense and nonsense in psychotherapy: The challenge of hypnosis. Oxford: Pergamon.

Chang, J., Sala, J., Habich, K., Pein, G., Samatakis, K., \& Broenson, R. (2012). The association of sleep duration and depressive symptoms in rural communitie of Missouri, Tennesse, and Arkansas. Journal of Rural Health, 28(3), 268-276. http://dx.doi.org/10.1111/j.1748-0361.2011.00398.x

Davis, M., Eshelman, E., \& Mckay, M. (2000). The relaxation \& stress reduction workbook (5th ed.). Oakland: New Harbinger Publications, Inc.

Freeman, A. (2007). The use of homework in cognitive behavior therapy: Working with complex anxiety and $\begin{array}{llll}\text { insomnia. Cognitive and } & \text { 261-267. }\end{array}$ http://dx.doi.org/10.1016/j.cbpra.2006.10.005

Fromm, E., \& Shor, R. E. (1979). Hypnosis: developments in research and new perspective. New York: Aldine.

Hamilton, N. A., Gallagher, M. W., Preacher, K. J., Stevens, N., Nelson, C. A., Karlson, C., \& McCurdy, D. (2007). Insomnia and Well-Being. Journal of Counsulting and Clinical Psychology, 75(6), 939-946. http://dx.doi.org/10.1037/0022-006X.75.6.939

Harrison, G. E., \& van Haneghan, J. P. (2011). The gifted and the shadow of nigh Dabrowski's overexcitabilities and their correlation to insomnia, death anxiety, and fear of the unknown. Journal for the Education of the Gifted, 34(4), 669-697. http://dx.doi.org/10.1177/016235321103400407

Hawkims, P., \& Polemikos, N. (2002). Hypnosis Treatment of sleeping problem in children experiencing Loss. Coontemporary Hypnosis, 19(1), 18-25. http://dx.doi.org/10.1002/ch.236

Goldstein, T. R., \& Bridge, J. A. (2008). Sleep Disturbance Preceding Completed Suicide. Adolescents Journal of Consulting and Clinical Psychology, 76(1), 84-91. http://dx.doi.org/10.1037/0022-006X.76.1.84

Kiecolt, G. J., Marucha, P. T., Atkinson, C., \& Glaser, R. (2002). Hypnosis as a Modulator or cellular Immune Dysregulaton during Acute stress. Journal of Counselling and clinical psychology, 29(4), 674-683.

Laplante, P. M. (1991). An investigation of alert self-hypnosis, hypnotic suggeslans, absorption, and reading comprehension among college students. Dissertation Abstracts.

LeCron, L. M. (1971).The complete guide to hypnosis. New York: Harper Row.

Liz, S. (2006). Insomnia drugs: A wake-up call? Academic Search premier, USA today.

Marntani, R., \& cirnino, A. (2002) A Primer of complementary and Alternative Medicine and its Relevance in the Treatment of mental health problems. Psychiatr Quarterly, 73(4), 367-381. http://dx.doi.org/10.1023/A:1020472218839

Mead, M. (2006). Coping with insomnia. Practice Nurse, 31(9), 22-26.

Milner, C., \& Belicki, K. (2010). Assessment and treatment of insomnia in adults: Aguide for clinicians. Journal of counselling \& development, 88(2), 236-245. http://dx.doi.org/10.1002/j.1556-6678.2010.tb00015.x

Miller, M. M. (1979).Therapeutic hypnosis. New York: Human sciences.

Sing, C. Y., \& Womng, W. S. (2010). Prevalence of insomnia and its psychological correlation among college students in Hong Kong. Journal of American College Health, 59(3), 179-182. http://dx.doi.org/10.1080/07448481.2010.497829

Sprinkle, R. L. (1997). Anxiety management training through self- hypnosis.

Strus, R. A. (1998.). Creative self- hypnosis: new, wide-awake,nontrance techniques to empower your life and work. New York: Prentice Hall.

Young, G. K. (1996). Hypnosis as an adjunctive modality in the relapse prevention component of an alcoholism treatment program. Dissertation Abstraccts.

Younus, J., Simpson, I., Collins, A., \& Wong, X. (2003). Mind control of menopause. Women's Health Issues, 13(2), 74-79. http://dx.doi.org/10.1016/S1049-3867(02)00196-2

Vail-Smith, K., Felts, W, M., \& Becker, C. (2009). Relationship between Sleep Quality and Health Risk Behaviors in Undergraduate College Students. College Student Journal, 4(3), 924-930. 
Waxman, D. (1985). Modern trends in hypnosis. New York: Plenum Press. http://dx.doi.org/10.1007/978-1-4684-4913-6

Wong, X. (2003). Mind control of menopause. Women's Health Issues, 13(2), 74-79. http://dx.doi.org/10.1016/S1049-3867(02)00196-2

\section{Copyrights}

Copyright for this article is retained by the author(s), with first publication rights granted to the journal.

This is an open-access article distributed under the terms and conditions of the Creative Commons Attribution license (http://creativecommons.org/licenses/by/3.0/). 